\title{
Epidemiology of human and animal rabies in Algeria
}

\begin{abstract}
In this paper we reviewed research paper regarding human and animal rabies in Algeria with the aim of describing the incidence in human and the prevalence of animal rabies in Algeria with emphasis on epidemiological assessment of the deployed control measures and zoonotic potential. Comparatively, the number of post-exposure prophylaxis (PEP) cases reported from Algeria followed a similar trend in dogs, highlighting the impact of this animal reservoir on the public health implication of the disease in Algeria. Human PEP incidence may reflect the true epidemiological situation of rabies in animals. In Algeria, an annual average of 85,000 people are exposed to rabies yearly through dog bites and eventually subjected to PEP procedure. From 2006 to 2013, an average of 20 human deaths from rabies were reported. The dog has proven to be the source of infection to humans with an average $99 \%$ of the reported case. Collaboration between the department of public health and department of veterinary services is important for the control of rabies in animals and thereby eliminate transmission to humans.
\end{abstract}

Keywords: algeria, animal, rabies, human, vaccination
Volume 4 Issue I - 2016

\author{
Moustafa Kardjadj \\ Ecole Supérieure en Science de l'Aliments (ESSA),Algeria
}

Correspondence: Kardjadj Moustafa, Ecole Supérieure en Science d'Aliments,Algiers, Algeria, Tel +2137 969| 5906, Email drkardjadj@live.fr

Received: October 16, 2016 | Published: November 08, 2016

\section{Introduction}

Rabies is a lethal form of encephalitis and enzootic in many parts of Asia and Africa where it poses a significant veterinary and public health concern. ${ }^{1,2}$ Rabies is caused by neurotropic viruses of the genus Lyssavirus. It is a zoonotic infection mainly transmitted through the saliva of infected animal. Extensive efforts in developed countries (America and Europe) have largely controlled dog and fox rabies however, it remains enzootic in many regions of the world. ${ }^{3}$ Rabies prevention methods have been known since the time of Louis Pasteur and have subsequently evolved to effective schedules of post-exposure prophylaxis (PEP). ${ }^{2}$ Rabies transmission to humans is usually through saliva via the bite of an infected animal. Once symptoms of rabies are exhibited in humans, the disease is almost always fatal. Worldwide, about 15 million people require PEP every year. However, the estimated number of human deaths of 55, 000 per year globally due to rabies remains high. ${ }^{4}$ Over $95 \%$ of these human rabies cases are concentrated in Asia and Africa, and dogs are responsible for $99 \%$ of these transmission cases. ${ }^{4,5}$ Target dog control programs have been shown to effectively reduce the risk of rabies virus transmission to humans but their design and implementation still poses a number of challenges to government of developing countries. ${ }^{6}$

In Algeria, rabies is considered a major zoonosis and the veterinary authorities consider it a priority in the national committee agenda for the fight against zoonosis since $1984 .^{7}$ To deal with this disease, the national veterinary authority introduced, in 1996, a prevention and control program based mainly on two actions; mandatory vaccination of domestic carnivores and reduce the population of stray carnivores, which are a major cause of human infection. For the economic losses caused by the infringement of bovine species, vaccination was made compulsory since 2004 . This vaccination campaign starts annually in March in conjunction with that of FMD. ${ }^{8}$

The epidemiology of rabies in Algeria has not been well

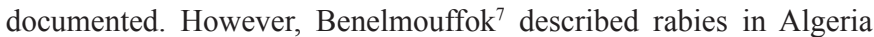
from 1970 to 2003. He showed that from 2000-2003 the mean number of PEP and human death to rabies was 55, 873 and 19 cases per year, respectively. As for animals the mean number of rabies reported cases for all species was 947. Furthermore, he stated that rabies was widely present in Northern Algeria and there was no case (animals or human) in the Sahara region at the south of Algeria. The objectives of this study was to describe the epidemiology of human and animal rabies in Algeria between from 2006-2013 with special emphasis on the assessment of the deployed control measures, using data obtained from the Algerian ministry of agriculture and rural development (MADR) and the Algerian ministry of public health (MPH).

\section{Methodology}

Algeria is the largest country in Africa. It is located between latitudes $19^{\circ}$ and $37^{\circ} \mathrm{N}$ and longitudes $9^{\circ} \mathrm{W}$ and $12^{\circ} \mathrm{E}$. It is bounded by the Mediterranean Sea to the north, Tunisia to the east, Morocco to the west, Mali and Niger to the south. It has a long coastline at the Mediterranean Sea $(1600 \mathrm{~km})$; Most of the coastal area (northern region) is hilly, sometimes even mountainous. South of the northern region is the Sahara Desert. Algeria has 2,147,570 $\mathrm{km}^{2}$ area of land with about 40 million people. More than $80 \%$ of the people live in coastal areas. ${ }^{9}$ Administratively, Algeria is divided into 48 districts but for the present study and according to geographical and farming management specificity, five regions were delimited and each region contained 7 to 12 districts; north-central $\left(35.3^{\circ}-36.8^{\circ} \mathrm{N}\right.$ and $\left.1^{\circ} \mathrm{E}-4.7^{\circ} \mathrm{E}\right)$, northwestern $\left(35^{\circ}-36.3^{\circ} \mathrm{N}\right.$ and $\left.2^{\circ} \mathrm{W}-1^{\circ} \mathrm{E}\right)$, north-eastern $\left(35.3^{\circ}-37^{\circ} \mathrm{N}\right.$ and $\left.4.7^{\circ} \mathrm{E}-8.5^{\circ} \mathrm{E}\right)$, steppe region $\left(33^{\circ}-35.3^{\circ} \mathrm{N}\right.$ and $\left.2^{\circ} \mathrm{W}-8.5^{\circ} \mathrm{E}\right)$. and the Sahara $\left(19^{\circ}-33^{\circ} \mathrm{N}\right.$ and $\left.8.8^{\circ} \mathrm{W}-12^{\circ} \mathrm{E}\right)$.

This is a descriptive retrospective study. The study included reports of national animal rabies, and human exposures to potentially rabid animals and reports of human death to rabies in Algeria from 1 January 2006 to 31 December 2013 where PEP was indicated (PEP consists of both rabies vaccine and rabies immune globulin, if required). Peer-reviewed literature, epidemiological reviews and expert judgment were reviewed for evidence to support a reduced (four intramuscular doses at days $0,3,7$ and 14) vaccine schedule in healthy patients during rabies post-exposure prophylaxis (PEP). ${ }^{6}$ The number of dogs in Algeria is unknown. Very few people in the rural 
areas have pet dogs while in major towns and cities there are pet dogs. There are large numbers of stray dogs roaming freely on the street, human dwelling places and animal sheds. Stray dogs eat garbage, discarded food, dead animal carcasses including placenta and aborted fetuses (Kardjadj M. personnel communication).

The number of reported cases of animal rabies per species, month and district from 2006-2013, as well as the number of vaccinated animals (cattle, dogs and cats) and the number of captured and euthanatized stray carnivores (dogs and cats) were retrieved from the Bulletin Vétérinaire; a monthly reports of the veterinary services office of the Algerian Ministry of Agriculture and Rural Development. ${ }^{8}$ Animal rabies diagnoses were conducted by the Algerian Institute of Veterinary Medicine using the rabies fluorescent antibody test (FAT) as described by Fehlner-Gardiner et al. ${ }^{10}$

The number of human exposures to animals that required PEP administration, as well as the number of human death(per sex and district) were retrieved from the Epidemiology Bulletin; an annually reports of the public health institute, Algerian Ministry of Public Health. ${ }^{9}$ The Epidemiology Review data included demographics of the exposed persons, reported date, the animal types, the types of exposure (e.g. bite, nearby, etc.), the geographic locations of the exposure and the rabies statuses of the animal. Human rabies diagnosis using the FAT were preformed and post mortem carried out under medico-legal circumstances at Algerian Pasteur Institute (IPA). ${ }^{11}$ Counts and incidence rates for animal rabies and PEP administration were determined and analyzed based on species, month, district and the overall for the study period. Data cleaning and analysis were performed using MICROSOFT EXCEL (Microsoft Corporation, version 2007, Redmond, WA, USA).

\section{Finding}

\section{Human rabies (Table I)}

Data from the National Institute of Public Health (INSP) revealed an annual mean of 20 human rabies deaths (Table 1). These cases were mostly observed during spring and summer periods among the age ranged 2 to 68 years old. Sex-wise analysis showed a male predominance possibly because of professional inclination. This survey also revealed that $99 \%$ of PEP cases originated from dogs, of which the stray dogs account for $65 \%$ of it. However, the total number of stray dogs in Algeria is unknown. Very few people in the rural areas have pet dogs while in major towns and cities most households own pet dogs. The distribution of human rabies was observed to be exclusively present in the northern region (east, center and west). The high density of carnivores' population in these areas has been associated with the high number of cases.

\section{Animal rabies (Table 2)}

Dog is the true reservoir of rabies virus in Algeria with an average of 467 cases recorded between 2006 and 2013. Followed by cattle which were victims of dog bite with an average of 210 registered cases. Although cats are carnivores but had a lower rate compared with ruminants and equide. Animal rabies in Algeria has evolved to be endemic and spread over the entire country, particularly in the north where dog population is higher. This was observed from an average of 875 cases reported annually (all species).For the entire study period (2006-2013), the highest number of cases (54\%) was from the eastern part of the country followed by $33 \%$ from the central region and $14 \%$ from the western region. Nonetheless, no single case was reported or recorded from the southern province.

Table I The annual human rabies death and PEP in Algeria

\begin{tabular}{llllll}
\hline Years & $\begin{array}{l}\text { Number of } \\
\text { PEP cases }\end{array}$ & $\begin{array}{l}\text { PEP from history of } \\
\text { domestic dog bite(\%) }\end{array}$ & $\begin{array}{l}\text { PEP from history of } \\
\text { stray dog bite(\%) }\end{array}$ & $\begin{array}{l}\text { PEP from other } \\
\text { animals' bite }\end{array}$ & $\begin{array}{l}\text { Death from rabies } \\
\text { human (male) }\end{array}$ \\
\hline 2006 & 47,583 & $21,412(45 \%)$ & $26,150(5(\%)$ & $21(<0.01 \%)$ & $11(14)$ \\
2007 & 76,765 & $23,025(30 \%)$ & $55,714(70 \%)$ & $26(<0.01 \%)$ & $24(24)$ \\
2008 & 74,321 & $24,525(33 \%)$ & $41,773(6 \mathrm{e} \%)$ & $23(<0.01 \%)$ & $25(25)$ \\
2009 & 75,988 & $15,179(20 \%)$ & $60,759(80 \%)$ & $32(<0.01 \%)$ & $12(12)$ \\
2010 & 88,966 & $28,689(30 \%)$ & $60,252(70 \%)$ & $25(<0.01 \%)$ & $13(13)$ \\
2011 & 97,321 & $39,387(38 \%)$ & $57,903(6 e \%)$ & $31(<0.01 \%)$ & $16(16)$ \\
2012 & 109,811 & $35,934(20 \%)$ & $73,849(80 \%)$ & $28(<0.01 \%)$ & $17(17)$ \\
2013 & 114,652 & $39,672(31 \%)$ & $74,690(69 \%)$ & $20(<0.01 \%)$ & $15(15)$ \\
\hline
\end{tabular}

Table 2 Rabies annual cases all species combined

\begin{tabular}{llllllll}
\hline Year & Canine(dog) & Bovine & Caprine/Ovine & Feline & Equide & Other & Overall \\
\hline 2006 & 495 & 221 & 89 & 37 & 85 & 9 & 936 \\
2007 & 636 & 244 & 105 & 42 & 79 & 7 & 1113 \\
2008 & 715 & 203 & 121 & 49 & 110 & 14 & 1212 \\
2009 & 432 & 217 & 61 & 20 & 35 & 16 & 781 \\
2010 & 302 & 137 & 72 & 34 & 58 & 12 & 652 \\
2011 & 381 & 242 & 90 & 38 & 48 & 8 & 807 \\
2012 & 407 & 219 & 63 & 22 & 61 & 17 & 789 \\
2013 & 375 & 198 & 74 & 24 & 32 & 11 & 714 \\
Mean & 467.875 & 210.125 & 84.375 & 33.25 & 63.5 & 11.75 & 875.5 \\
\hline
\end{tabular}


In Table 3, euthanasia of stray carnivores (dogs and cats) started in 2007 and by 2013, a total of 227,488 subjects, with a mean of 28431 stray carnivores were euthanized per year. Furthermore, vaccination of domestic carnivores also increased significantly between 2006 and 2013, with a mean of 45644 domestic dogs and cats vaccinated per year. Nevertheless the number of human and animal cases reported each year remained high. From 2006 to 2013, each year a mean of 523682 cattle were vaccinated however, there was an interruption in vaccination coverage in 2008 and 2010 due to unavailability of vaccines. Nevertheless, the incidence of this disease in this species remains fairly steady.

Table 3 The annual animal rabies prophylaxis in Algeria

\begin{tabular}{llll}
\hline Year & $\begin{array}{l}\text { Cattle } \\
\text { vaccination }\end{array}$ & $\begin{array}{l}\text { Domestic } \\
\text { carnivore } \\
\text { vaccination }\end{array}$ & $\begin{array}{l}\text { Stray carnivore } \\
\text { euthanatized }\end{array}$ \\
\hline 2006 & 565,664 & 20,058 & 33,774 \\
2007 & 802,770 & 25,768 & 21,534 \\
2008 & 7,200 & 28,952 & 52,506 \\
2009 & 795,872 & 49,431 & 37,310 \\
2010 & 36,336 & 55,332 & 26,242 \\
2011 & 334,053 & 40,805 & 23,014 \\
2012 & 833,079 & 79,255 & 11,952 \\
2013 & 814,485 & 65,557 & 21,116 \\
Mean & $523,682.38$ & $45,644.75$ & 28,431 \\
\hline
\end{tabular}

\section{Discussion and recommendation}

In Algeria, annual averages of 85,000 people are exposed to rabies yearly through dog bites and eventually go through the procedure of post exposure prophylaxis. From 2006 to 2013, an average of 20 human deaths from rabies was reported. The dog in Algeria has proven to be the source of infection to humans with an average $99 \%$ of the reported case within the present study period. To deal with this disease, a national control program was initiated in 1996, to reduce the number of wandering animal population and carry out vaccination of all domestic carnivores. Since 2004, vaccination has become mandatory for the bovine species also. The number of vaccinated domestic carnivores increased from 20,058 in 2006 to 65,375 subjects in 2013, despite the execution of preventive program. Unlike the carnivores that were slaughtered during the 2013 operation a total of 21,116 stray dogs and cats, against 33,774 in 2006. Stray carnivores represent an enormous risk to animal health and public health, and the euthanasia operations have been insufficient.

Rabies is a zoonotic disease with a serious threat to both veterinary and public health. Due to its high morbidity and mortality, it exacts a heavy social and financial burden on the Algerian state. In animals, they cause significant economic losses, related to the reduction and loss in production and mortality in humans because of its fatality. There are large numbers of stray dogs roaming freely on the street, human dwelling places and animal sheds. Stray dogs eat garbage, discarded food, dead animal carcasses including placenta and aborted fetuses.

Zoonosis diseases are a serious threat to both veterinary and public health. Due to its high morbidity and mortality, it exacts a heavy social and financial burden on the Algerian state. In animals, they cause significant economic losses, related to the reduction and loss in production and mortality in humans because of its fatality. The dog has been a common reservoir for rabies and also visceral Leishmaniasis, Leptospirosis and Echinococcosis. The occurrence of these diseases is favorable with the presence of uncontrolled proliferation of household waste deposits particularly in and around urban areas. Therefore, prevention and control can only be successful through inter-sectoral collaboration, continuous and sustained interventions focused on several aspects; animal, human and environmental, so as to:

i. Ensure better management of household waste;

ii. Fight against stray animals by periodic slaughter;

iii. Enforce the mandatory nature of the anti-rabies vaccination of carnivores;

iv. Precede to the realization of canines pounds at a rate of at least one by district.

v. Encourage the citizen to be an active player in prevention through health education;

vi. Awareness programs and public outreach remain essential elements for the success of campaigns and eradication of this disease.

Control and eradication of rabies is a measure desired by many countries where the disease is endemic. However, this result is difficult and expensive, taking into account the specific climatic, geographical, socio-economic, animal ownership, technical resources and personnel, prevalence of disease, as well as the strict commitment to vaccinations programs. In this sense, developing countries have major difficulties both in setting and achieving success in their programs of control and eradication of this disease. Collaboration between the department of health (MPH) and department of Veterinary Services (MADR) is important for the control of animal rabies and thereby eliminate transmission to humans. Periodical joint meetings will be of mutual benefit for both services and the general public.

\section{Acknowledgements}

None.

\section{Conflict of interest}

Author declares that there is no conflict of interest.

\section{References}

1. Knobel DL, Cleaveland S, Coleman PG, et al. Re-evaluating the burden of rabies in Africa and Asia. Bull World Health Organ. 2005;83(5):360-368.

2. WHO. Rabies vaccines: WHO position paper--recommendations. Vaccine. 2010;28(44):7140-7142.

3. Anderson A, Shwiff S. The cost of canine rabies on four continents. Transbound Emerg Dis. 2013;62(4):446-452.

4. Hampson K, Coudeville L, Lembo T, et al. Estimating the global burden of endemic canine rabies. PLoS Negl Trop Dis. 2015;9(4):e0003709.

5. Lembo T, Attlan M, Bourhy H, et al. Renewed global partnerships and redesigned roadmaps for rabies prevention and control. Vet Med Int 2011;2011:923149. 
6. Begashaw B, Tonamo A. Rabies Prevalence, Prevention and Clinical Features in Case of Developing Countries: Article Review. Developing countries study. 2016;6(2):116-122.

7. Benelmouffok A. Epidémiologie de la Rage en Algérie. Bull Acad Vét Tome. France; 2004; 157: N²

8. MADR. Ministère de l'Agriculture et de Développement Rural, Algérie; 2014 .
9. MPH. Ministère de la santé publique, Algérie; 2014.

10. Fehlner-Gardiner CF, Muldoon S, Nadin-Davis A, et al. Laboratory diagnosis of rabies in Canada for calendar year 2006. Can Vet $J$ 2008;49(4):359-361.

11. Acha NP, Szyfres B. Zoonoses and Communicable Diseases Common to Man and Animals. 3rd ed. Washington, DC: Pan American Health Organization (PAHO). 2003;1:1-395. 